\title{
La última dictadura argentina en el aula: entre materiales, textos y lecturas
}

The Last Argentine Dictatorship in the Classroom: Materials, Texts and Readings

Paula González*

\section{RESUMEN}

Este trabajo se acerca a la historia argentina reciente en las aulas para analizar la práctica docente cotidiana. Presenta un estudio de caso de un docente del conurbano bonaerense que trabaja en una institución escolar que alienta el tratamiento de la última dictadura, que tiene formación actualizada y que utiliza variados recursos. En esas condiciones, ¿qué materiales trabaja?, ¿qué textos introduce?, ¿qué lecturas propone? Este artículo presenta una serie de respuestas a los interrogantes anteriores y se propone subrayar: i) la naturaleza productiva e inventiva de la práctica docente; ii) la importancia de la materialidad en la enseñanza; iii) la potencia de diferentes materiales, textos y lecturas que posibilitan el trabajo con diversos lenguajes, memorias y debates.

Palabras clave: Historia argentina reciente; dictadura (1976-1983); prácticas; enseñanza; materialidad.

\begin{abstract}
This article while approaching to recent history in the classroom to analyse the daily teaching practices. It will present a case study of a History teacher from Buenos Aires outskirts, who works in a school that encourages the public treatment of the last dictatorship, who has updated knowledge, and possess (and dares to use) various resources. So, what materials does this teacher select? What texts does he choose? What readings does he propose? This paper will present a series of answers to the previous questions and will propose to emphasize: i) the productive and inventive nature of teaching practices; ii) the importance of materiality in history teaching; iii) the power of different materials, texts and readings that make possible to work with different languages, representations and debates.

Keywords: Argentina recent history; dictatorship (1976-1983); practices; teaching; materiality.
\end{abstract}

\footnotetext{
* Investigadora docente adjunta regular, Universidad Nacional de General Sarmiento (UNGS) e Investigadora adjunta, Consejo Nacional de Investigaciones Científicas y Tecnicas (Conicet). Buenos Aires, Argentina. gonzalezamorena@gmail.com
} 
La historia argentina reciente - particularmente la última dictadura (1976-1983) - tiene un lugar importante en la escuela secundaria actual, desde la Ley Federal de Educación de 1993 y, sobre todo, a partir de la sanción de la Ley de Educación Nacional en 2006 (hoy vigente). A este respecto, se ha indagado su inclusión en la legislación educativa y los sucesivos diseños curriculares así como su presentación en los libros de texto escolares. Al mismo tiempo, varios trabajos han indicado las tensiones en torno a su tratamiento escolar por tratarse de un pasado próximo, controversial, traumático y abierto. Asimismo, y especialmente en los primeros años de su inclusión en el currículo escolar, se han señalado los inconvenientes que han enfrentado muchos profesores: falta de formación y actualización, escasez de referencias historiográficas, materiales insuficientes, conflictos en las instituciones escolares, entre otros aspectos (De Amézola, 2006; De Amézola; Carlos; Geoghegan, 2006). Así, entonces, y como para otros temas relativos a la enseñanza de la historia, se ha indagado menos acerca de lo que sucede en las aulas. ${ }^{1}$ No obstante, en los últimos años se ha avanzado al respecto, penetrando en la cotidianeidad escolar y observando las prácticas docentes y escolares (Higuera Rubio, 2010; Billán, 2015; Pappier, 2017).

Este trabajo se inscribe en esta última perspectiva, es decir, en la de acercarse a la historia reciente en las aulas para analizar la práctica docente cotidiana. Para ello, presenta un estudio de caso de un docente del conurbano bonaerense que trabaja en una institución escolar que alienta el tratamiento de la última dictadura, que tiene formación actualizada, que conoce (y se atreve a usar) variados recursos. En esas condiciones, ¿qué materiales trabaja?, ¿qué textos introduce?, ¿qué lecturas propone?

Este artículo presenta una serie de respuestas a los interrogantes anteriores y se propone subrayar: i) la naturaleza productiva e inventiva de la práctica docente; ii) la importancia de la materialidad en la enseñanza; iii) la potencia de diferentes materiales, textos y lecturas en torno a la última dictadura que posibilitan el trabajo con diversos lenguajes, representaciones, memorias y debates. En última instancia, el trabajo aspira a contribuir a la formación docente en historia desde la investigación de las prácticas de los profesores en las aulas. 


\section{SOBRE LAS PRÁCTICAS DOCENTES EN TORNO A LA ÚLTIMA}

\section{DICTADURA: PRESCRIPCIONES Y PROPUESTAS}

Indagar la enseñanza de la historia reciente en las aulas excede el estudio de la normativa educativa o el análisis de las propuestas pedagógicas. No obstante, también es ineludible conocer en qué contexto - tanto político como didáctico - un docente construye su práctica puesto que son dimensiones que la atraviesan.

Por lo dicho, resulta clave señalar que la vigente Ley Nacional de Educación 26206 (en adelante LEN) sancionada en 2006, ha dado un lugar central a la historia argentina reciente - y particularmente la última dictadura - y a la construcción de la memoria. En efecto, en el propio cuerpo de esa ley se señalan como contenidos curriculares comunes a todas las jurisdicciones:

El ejercicio y construcción de la memoria colectiva sobre los procesos históricos y políticos que quebraron el orden constitucional y terminaron instaurando el terrorismo de Estado, con el objeto de generar en los/as alumnos/as reflexiones y sentimientos democráticos y de defensa del Estado de Derecho y la plena vigencia de los Derechos Humanos. (Argentina, ME, 2006a, p.19)

A partir de la LEN, los Núcleos de Aprendizajes Prioritarios (en adelante NAP) de alcance nacional también indicaron los siguientes contenidos relativos a la última dictadura para la educación secundaria básica:

El conocimiento de las características del terrorismo de Estado implementado en la Argentina por la dictadura militar de 1976-1983, y de su relación con la Guerra Fría y la aplicación de un modelo económico y social neoliberal. (Argentina, ME, 2006b, p.22)

Asimismo, en 2012, se aprobaron los NAP para la secundaria superior indicando que la escuela ofrecerá, entre otras, situaciones de enseñanza que promuevan en las y los estudiantes:

La comprensión del golpe cívico-militar de 1976 y del Terrorismo de Estado como plan sistemático para destruir a las organizaciones populares y disciplinar a la sociedad, creando las condiciones de implementación del modelo económico neoliberal. (Argentina, ME, 2012, p.7) 
Para la jurisdicción de la Provincia de Buenos Aires, la historia argentina reciente está incluida en los diseños curriculares de Historia de $5^{\circ}$ y $6^{\circ}$ año. Dentro del programa para $5^{\circ}$ año (común para todas las modalidades) los contenidos son los siguientes:

La última dictadura cívico-militar en la Argentina: represión, disciplinamiento social y política económica. La Dictadura y la sociedad: la búsqueda de la subordinación sin consenso. El movimiento de Derechos Humanos y la resistencia civil. La Dictadura y la economía: auge de la especulación financiera, crisis y endeudamiento externo. (PBA-DGCyE, 2011, p.20)

Para el programa de Historia de $6^{\circ}$ año - de las modalidades de Ciencias Sociales y Arte - se incluye la unidad 2 titulada "Los años 70. Movilización social y represión" con la indicación de que los estudiantes deberán elaborar proyectos de investigación en relación con los siguientes problemas historiográficos:

La emergencia de las organizaciones armadas. Sus idearios políticos. Los jóvenes y sus relaciones con el peronismo. Culturas y consumos juveniles. Militancia. Expansión y contracción económica. La espiral de la violencia. El derrocamiento del peronismo y el golpe de Estado cívico-militar. El terrorismo de Estado. La detención-desaparición de personas. La cultura del miedo. El golpe cívico-militar a la educación pública y la censura. El problema del exilio. El proceso de desindustrialización y sus consecuencias sobre el mercado y la economía interna. El impacto de las políticas neoliberales. El endeudamiento externo. Deportes, medios y política. La guerra de Malvinas. Los movimientos de Derechos Humanos. El rock nacional. Cine, teatro underground. (PBA-DGCyE, 2012, p.43)

En un sintético balance se puede señalar que, tanto en la legislación general como en los diseños curriculares, son visibles las marcas de las "políticas de memoria por parte del Estado" (Lvovich; Bisquert, 2008), llevadas adelante a partir de 2003: tanto por el uso de definiciones tales como "terrorismo de Estado" como por el lugar ganado por la propia historia reciente en el currículo.

Asimismo, y dado que aquí interesan los materiales, textos y lecturas, cabe reseñar que el propio diseño curricular de la Provincia de Buenos Aires prescribe, entre sus objetivos, incorporar diversidad de textos históricos que sean representativos de las distintas corrientes historiográficas; promover prácticas de escritura que propongan la elaboración de distintos géneros (informes, 
comentarios bibliográficos, ensayos etc.); incorporar, con distintos grados de complejidad, la enseñanza de la Historia a través de las Nuevas Tecnologías de la Información a los fines de que sean utilizados para el desarrollo de preguntas, formulación y tratamiento de problemas, así como para la obtención, el procesamiento y la comunicación de la información generada (PBA-DGCyE, 2011). Del mismo modo, al final del diseño, se incluyen referencias de páginas web y sugerencias didácticas donde son ponderados los materiales audiovisuales.

Por cierto, los libros de textos escolares también acompañan la enseñanza de la historia argentina reciente en la escuela. En efecto, aun con diferencias entre las diversas propuestas y más o menos fieles a los enunciados de los diseños curriculares según cada editorial, los libros para $5^{\circ}$ y $6^{\circ}$ año - especialmente aquellos utilizados en la Provincia de Buenos Aires - incluyen y desarrollan exhaustivamente la última dictadura militar. ${ }^{2}$ Del mismo modo, resulta importante aludir a la producción de materiales didácticos realizada por el ministerio de Educación de la Nación entre 2005 y 2015 dentro del programa Educación y Memoria, un programa que, además, se propuso incidir en el desarrollo curricular, en la formación de docentes y estudiantes así como en el fomento de experiencias de investigación desde las escuelas (Adamoli; Farias; Flachsland, 2015). Para el caso de la última dictadura, tal programa desarrolló el material "Pensar la dictadura: terrorismo de Estado en Argentina" en el que propuso preguntas, respuestas y propuestas para su enseñanza a través de diversos textos y materiales y diferentes consignas para buscar más información, reflexionar, discutir, analizar, investigar etc. ${ }^{3}$ Esta importante producción estuvo acompañada, además, por diversos materiales disponibles en el Portal Educativo Educ.ar, series y documentales en la señal televisiva "Canal Encuentro" del Ministerio de Educación, entre otros.

En suma, se trata de un marco normativo y pedagógico favorable al tratamiento de la última dictadura en las aulas aunque desde el discurso y las decisiones políticas del actual gobierno el clima sea adverso. ${ }^{4}$

Pero, como se ha dicho, interesa aquí destacar las prácticas docentes y, por lo mismo, cabe señalar qué perspectiva tomaremos para analizarlas. Sobre esta cuestión avanza el próximo apartado.

\section{SOBRE LAS PRÁCTICAS DOCENTES: MODOS DE VER}

Una investigación pionera en Argentina sobre prácticas docentes en la enseñanza de la historia fue realizada a fines de los años '80 por Silvia Finocchio 
e Hilda Lanza (1993). En ella, las autoras se propusieron analizar cómo se conforman las prácticas docentes a través de una aproximación a "los ámbitos que constituyen el discurso de los profesores de historia del nivel medio" (Finocchio; Lanza, 1993, p.97). A través del análisis de entrevistas a profesores y observaciones de clases en dos escuelas estatales de la Ciudad de Buenos Aires, las autoras delimitaron "los espacios a los que acude el docente de historia con el fin de tomar conceptos que le permitan armar su propio discurso y de encontrar su fuente de legitimación" (Finocchio; Lanza, 1993, p.102). De ese modo, señalaron la incidencia - no excluyente pero sí significativa - de: la formación docente, entendida como el proceso de aprendizaje de contenidos científicos referidos a la historia y de contenidos pedagógico didácticos que le permiten reproducir o construir nuevas formas de enseñar; la propuesta oficial, que engloba los proyectos, circulares, resoluciones, decretos y programas referidos a qué, cómo y cuándo enseñar; la conciencia de la historia, definida como la estructura de pensamiento mediante la cual el sujeto interpreta la historia como orientadora de sus prácticas sociales a través del tiempo; la concepción de la historia, entendida como el modelo historiográfico al que se adhiere y las consecuentes opciones teóricas y metodológicas que el mismo comprende; el universo de los textos escolares; el campo bibliográfico propio, es decir, el conjunto de lecturas más o menos sistemáticas realizadas y manifestadas por los docentes que pueden penetrar o no en la cotidianeidad escolar; las exclusiones, concebidas como las omisiones o rechazos significativos; el saber hacer que se constituye en la relación de los ámbitos anteriormente mencionados y que, a través de la práctica rutinaria, moldea la tarea en la cotidianeidad del aula.

Sin desconocer aportes más recientes en esta línea, ${ }^{5}$ retomo las dimensiones propuestas por Finocchio y Lanza (1993) y sumo otros elementos para pensar las prácticas docentes sobre todo en relación con el tratamiento de la historia argentina reciente (es decir, en un nuevo contexto educativo y frente a un contenido sensible).

Así, y a modo de balance, propongo considerar: i) el contexto con diversos espacios, tiempos y sedimentaciones, es decir, el socio-histórico - con sus representaciones, imaginarios, memorias en conflicto, referencias etc. -, el escolar - con su cultura y sus disciplinas escolares como marco de realización - el institucional - con las diversas "atmósferas de transmisión" de rechazo, aliento, omisión o rutina frente a la historia reciente; y el áulico, con sus coordenadas de tiempo y espacio y con los sujetos que construyen ese cotidiano; ii) la 
propuesta oficial, es decir, la normativa y diseños curriculares vigentes que señalan los objetivos y los contenidos a enseñar e incorporan los aportes de la historiografía académica, una propuesta que es apropiada por los docentes, es decir, es leída, traducida y reinterpretada; iii) los estudiantes, quienes - con sus sensibilidades, intereses, consumos, representaciones, expectativas y preguntas - moldean, interrogan y desafían a los docentes; iv) la materialidad, no solo de los libros escolares ni solo de materiales escritos e impresos sino también otros materiales digitales, visuales, audiovisuales, multimediales que, en diferentes lenguajes y soportes, son portadores y constructores de diversos saberes, representaciones y discursos sobre la historia; v) los profesores - con su biografías, formaciones, lecturas, representaciones, memorias, posicionamientos políticos, expectativas - en sus diálogos y vínculos - con otros colegas, con las comunidades educativas donde trabajan, con sus estudiantes -; y vi) el saber hacer de los profesores a partir del cual despliegan diversas estrategias y tácticas, dando cuenta de la "movilidad plural de intereses y artes de hacer". ${ }^{6}$

Desde luego, las dimensiones aquí apuntadas no son las únicas que hacen a la conformación de las prácticas docentes, pero sí considero que resultan significativas para enriquecer la mirada sobre ellas. Naturalmente, serían necesarias más palabras para dar cuenta de su incidencia con más profundidad, pero en el marco de este trabajo he preferido tomar una de ellas - la materialidad - con el fin de realizar la presentación del análisis y señalar las intersecciones y vínculos con las otras dimensiones antes enumeradas.

\section{SOBRE LAS PRÁCTICAS DOCENTES: UN ESTUDIO DE CASO}

Como anticipé, este trabajo se basa en un estudio de caso y en el uso de la narración de la práctica con sus conocidos límites y potencialidades. ${ }^{7} \mathrm{Y}$ es que en un trabajo así, las preguntas e inquietudes de la investigación van más allá del caso pero, a la vez, se requiere de un análisis en profundidad para una finalidad de largo plazo. Y ese propósito es comprender las prácticas docentes así como subrayar la centralidad de la materialidad en esa tarea. En tal sentido, un caso permite atender a las diversas dimensiones y características de la práctica docente así como las múltiples aristas de un oficio tan complejo. Asimismo, la narración permite una reconstrucción más cercana y vívida de la experiencia que se reconstruye.

Por lo dicho, tomé la práctica de un profesor de Historia a quien observé durante cinco clases consecutivas de dos horas reloj cada una en un curso de 
Historia de $6^{\circ}$ año en una escuela privada laica del conurbano bonaerense entre mayo y junio de 2017. Además de las observaciones, mantuve varias charlas antes y después de las clases; realicé una entrevista en profundidad al término de las observaciones, y compartimos una nueva charla posterior con las transcripciones de clases para comentar algunos aspectos puntuales. Asimismo, el profesor me facilitó su planificación, varias carpetas de sus estudiantes y diversos materiales de clases (trabajos prácticos, guías de lectura, evaluaciones etc.).

Dicho esto, es menester señalar que se trata de un docente que tiene formación de posgrado stricto sensu y continúa formándose; tiene mucho interés por la historia argentina reciente; posee saberes y consumos sobre el lenguaje audiovisual; le gusta su tarea de profesor; tiene una vasta experiencia en su oficio (dieciocho años de antigüedad); tiene buen vínculo con los estudiantes; trabaja en una institución que no limita su trabajo docente en torno a la historia reciente; tiene condiciones materiales - tanto personales como institucionales - que favorecen un uso intensivo de recursos visuales y audiovisuales (una TV en el aula a la cual conecta su computadora portátil). Además, el curso en el cual observé su tarea estaba compuesto por veintidós estudiantes, con buen clima y disposición hacia la materia (sin mostrar problemas de convivencia, disciplina, disposición para el trabajo o comprensión lectora).

Visto en perspectiva, se trata de un caso con condiciones que no son generalizadas en el contexto de la provincia de Buenos Aires. Más aún, pueden ser consideradas como ideales. No obstante, y como dije, no es el afán hacer generalizaciones a partir de este caso. Lo tomo, precisamente, para poder señalar algunos rasgos de la enseñanza de la historia desde las posibilidades y no desde los problemas, para poder pensar la enseñanza de la historia reciente cuando no está determinada por la falta de formación docente, por una atmósfera de transmisión adversa, por la ausencia de materiales u otros problemas, tensiones y limitaciones. Como dije, sobre esto, ya se ha escrito bastante y me interesa ir por otro camino y preguntar: cuando las condiciones favorecen el trabajo del docente sobre la última dictadura: ¿qué materiales trabaja?, ¿qué textos introduce?, ¿qué lecturas propone?

Desde luego, estas preguntas son apenas un recorte de todo lo que es posible pensar en torno a las prácticas de enseñanza en las aulas. No obstante, su elección no es fortuita ya que jerarquiza una dimensión usualmente menos atendida - tanto en la investigación como en la formación docente -, esto es, la materialidad en la enseñanza. ${ }^{8} \mathrm{Y}$ es que no es posible pensar el mundo 
educativo sin la cultura material, es decir, sin los objetos y materiales así como los saberes, prácticas y vínculos que proponen o potencian (Finocchio, 2016a).

Por lo dicho, opté concentrarme en los materiales, los textos y las lecturas en el análisis. Tal opción se funda también en que, en la secuencia de clases observadas, resultó notoria la centralidad y potencia de esa tríada, no solo por la multiplicidad de los materiales, la variedad de textos leídos (no solo escritos) y la significatividad de las lecturas propuestas sino porque todo ello fue de la mano y permitió una práctica relevante y significativa.

Para graficar lo central de ese aspecto en la práctica del docente observado se incluye el Cuadro 1. En él, se muestra la secuencia de clases desde mi mirada. Es decir, no se trata de la planificación del profesor sino de mi lectura sobre las clases que tuve la oportunidad de observar. Antes de abocarme al análisis de la práctica desde la materialidad, cabe indicar dos cuestiones de este caso.

Por un lado, es interesante subrayar que el docente toma en cuenta el diseño curricular (expuesto en el apartado 2) pero realiza su propia selección y secuenciación de contenidos. Su práctica muestra, entonces, lo inventivo y productivo de la práctica docente: pondera temas, descarta otros, dedica tiempos, profundiza aspectos según sus criterios, su contexto de trabajo, sus estudiantes y lo que cree que deben aprender, sus lecturas, su biografía, su formación, sus lecturas, sus intereses, su saber hacer etc.

Por otra parte, es significativo señalar que lo potente y diferente de esta secuencia de clases no está en las actividades o estrategias: si se observa el cuadro, las mismas no presentan gran variedad e incluso podrían ser tildadas de "tradicionales" (guía de preguntas, explicación, diálogo). Tal cuestión resulta importante para tener en cuenta los límites de ciertas miradas sobre las prácticas docentes (en historia u otras disciplinas escolares) que se concentran en el "qué" se enseña y "cómo" y desatienden "con qué" se enseña y "para qué" determinados contenidos. En este sentido, la mirada sobre los materiales, textos y lecturas da como resultado una práctica muy diferente si se compara con las actividades solamente.

Ahora bien, de todo lo trabajado en la secuencia de clases (como se expone en el cuadro anterior), voy a detenerme en los materiales, textos y lecturas de la primera clase de la secuencia didáctica (y del conjunto de clases observadas): la dedicada al golpe de Estado del 24 de marzo de 1976 y la instauración de la última dictadura. Y lo haré narrando la clase, reproducciones extractos de transcripciones y sumando notas de observación y de la entrevista y las charlas mantenidas con el docente. 
Cuadro 1 - Clases observadas: materiales, textos, lecturas y actividades (Elaboración propia)

\begin{tabular}{|c|c|c|c|c|}
\hline Clase & $\begin{array}{c}\text { Materiales / } \\
\text { soportes }\end{array}$ & Textos & Lecturas & Actividades y estrategias \\
\hline \multirow[t]{5}{*}{$\begin{array}{c}\text { 1. La } \\
\text { última } \\
\text { dictadura }\end{array}$} & $\begin{array}{l}\text { Audiovisual } \\
\text { Film } \\
\text { documental }\end{array}$ & $\begin{array}{l}\text { "La república } \\
\text { perdida } 2 "\end{array}$ & $\begin{array}{l}\text { Cinematográfica e } \\
\text { histórica Causas del } \\
\text { golpe. Violencia } \\
\text { política. “Teoría de los } \\
\text { dos demonios". }\end{array}$ & Guía de preguntas. \\
\hline & $\begin{array}{l}\text { Escrito } \\
\text { impresso } \\
\text { Texto } \\
\text { académico- } \\
\text { divulgativo }\end{array}$ & $\begin{array}{l}\text { "El tiempo del } \\
\text { proceso", de } \\
\text { H. Quiroga }\end{array}$ & $\begin{array}{l}\text { Histórica e } \\
\text { historiográfica. } \\
\text { Causas del golpe. } \\
\text { Violencia. } \\
\text { "Teoría de los dos } \\
\text { demonios". }\end{array}$ & $\begin{array}{l}\text { Explicación del } \\
\text { profesor. }\end{array}$ \\
\hline & $\begin{array}{l}\text { Escrito } \\
\text { impreso } \\
\text { Texto } \\
\text { periodístico. }\end{array}$ & $\begin{array}{l}\text { ¿Por qué vuelven } \\
\text { los } 70 ? ”, \text { de } \\
\text { F. Lorenz }\end{array}$ & $\begin{array}{l}\text { Historiográfica y } \\
\text { política. } \\
\text { "Teoría de los dos } \\
\text { demonios". } \\
\text { Luchas por la memoria. }\end{array}$ & $\begin{array}{l}\text { Diálogo } \\
\text { docente-estudiantes. }\end{array}$ \\
\hline & Mapa & $\begin{array}{l}\text { Mapa de } \\
\text { dictaduras en AL } \\
\text { años } 70-80\end{array}$ & $\begin{array}{l}\text { Histórica. Contexto } \\
\text { regional y mundial: } \\
\text { "guerra fría" }\end{array}$ & \\
\hline & $\begin{array}{l}\text { Escrito } \\
\text { impreso } \\
\text { Fuentes } \\
\text { primarias }\end{array}$ & $\begin{array}{l}\text { Comunicados de la } \\
\text { Junta Militar }\end{array}$ & $\begin{array}{l}\text { Histórica. Prohibiciones } \\
\text { y castigos. }\end{array}$ & $\begin{array}{l}\text { Tarea. Guía de } \\
\text { preguntas. }\end{array}$ \\
\hline \multirow[t]{3}{*}{$\begin{array}{l}\text { 2. Política } \\
\text { represiva }\end{array}$} & $\begin{array}{l}\text { Escrito } \\
\text { impreso } \\
\text { Texto } \\
\text { académico- } \\
\text { divulgativo }\end{array}$ & $\begin{array}{l}\text { "El tiempo del } \\
\text { proceso" }\end{array}$ & $\begin{array}{l}\text { Histórica e } \\
\text { historiográfica. } \\
\text { Mecanismos de la } \\
\text { política represiva. } \\
\text { Sociedad civil frente a la } \\
\text { dictadura. }\end{array}$ & $\begin{array}{l}\text { Guía de preguntas. } \\
\text { Explicación del } \\
\text { profesor. }\end{array}$ \\
\hline & Visual & $\begin{array}{l}\text { Fotografías de } \\
\text { centros } \\
\text { clandestinos y de } \\
\text { detenidos } \\
\text { desaparecidos }\end{array}$ & $\begin{array}{l}\text { Histórica. } \\
\text { Centros clandestinos } \\
\text { de detención }\end{array}$ & $\begin{array}{l}\text { Diálogo docente- } \\
\text { estudiantes. }\end{array}$ \\
\hline & Audiovisual & $\begin{array}{l}\text { Testimonio en el } \\
\text { Juicio a las juntas }\end{array}$ & $\begin{array}{l}\text { Histórica. Sistema } \\
\text { represivo: tortura, } \\
\text { desaparición, robo. }\end{array}$ & \\
\hline
\end{tabular}


continuación

\begin{tabular}{|c|c|c|c|c|}
\hline $\begin{array}{l}\text { 3. Política } \\
\text { económica }\end{array}$ & $\begin{array}{l}\text { Audiovisual } \\
\\
\text { Escrito } \\
\text { impreso } \\
\text { Visual }\end{array}$ & $\begin{array}{l}\text { Film "Las AAA } \\
\text { son las tres armas" } \\
(1979)^{9} \\
\text { Texto escolar } \\
\text { Gráfico estadístico }\end{array}$ & $\begin{array}{l}\text { Histórica. } \\
\text { Porcentaje de } \\
\text { desaparecidos jóvenes y } \\
\text { trabajadores } \\
\text { Histórica. Relación } \\
\text { entre sistema represivo } \\
\text { y política económica. } \\
\text { Histórica. Modelo } \\
\text { económico } \\
\text { Histórica. Crecimiento } \\
\text { de deuda externa, } \\
\text { pobreza y especulación } \\
\text { financiera. }\end{array}$ & $\begin{array}{l}\text { Explicación del } \\
\text { profesor. } \\
\text { Diálogo docente- } \\
\text { estudiantes. }\end{array}$ \\
\hline $\begin{array}{l}\text { 4. Política } \\
\text { económica }\end{array}$ & $\begin{array}{l}\text { Visual y } \\
\text { escrito }\end{array}$ & $\begin{array}{l}\text { Tapas de prensa de } \\
\text { la declaración de la } \\
\text { guerra de } \\
\text { Malvinas }^{10}\end{array}$ & $\begin{array}{l}\text { Histórica. La prensa } \\
\text { frente a la guerra. }\end{array}$ & $\begin{array}{l}\text { Guía de preguntas. } \\
\text { Explicación del } \\
\text { profesor. }\end{array}$ \\
\hline $\begin{array}{l}\text { Guerra de } \\
\text { Malvinas }\end{array}$ & $\begin{array}{l}\text { Visual } \\
\text { Escrito } \\
\text { impreso } \\
\text { Visual }\end{array}$ & $\begin{array}{l}\text { Fotografía de } \\
\text { Galtieri en la Plaza } \\
\text { de mayo }^{11} \\
\text { Testimonios de } \\
\text { soldados } \\
\text { Fotografía de } \\
\text { mujeres en } \\
\text { Malvinas }^{12}\end{array}$ & $\begin{array}{l}\text { Consenso social. } \\
\text { Histórica. Condiciones } \\
\text { en el campo de batalla. } \\
\text { Histórica. Participación } \\
\text { de la mujer. }\end{array}$ & $\begin{array}{l}\text { Diálogo docente- } \\
\text { estudiantes. }\end{array}$ \\
\hline 5. Síntesis & Audiovisual & $\begin{array}{l}\text { TV por la } \\
\text { identidad, capítulo } \\
3 \text {, "Nietos de la } \\
\text { esperanza"13 }\end{array}$ & $\begin{array}{l}\text { Histórica y } \\
\text { cinematográfica. } \\
\text { Síntesis de los diversos } \\
\text { aspectos trabajados a } \\
\text { partir de una historia } \\
\text { de vida. }\end{array}$ & $\begin{array}{l}\text { Guía de preguntas. } \\
\text { Explicación del } \\
\text { profesor. Diálogo } \\
\text { docente-estudiantes. }\end{array}$ \\
\hline
\end{tabular}




\section{SOBRE LAS PRÁCTICAS DOCENTES: ENTRE}

\section{MATERIALES, TEXTOS Y LECTURAS}

La primera clase de la secuencia comienza con la presentación del tema nuevo. El profesor anuncia que: trabajarán con "la dictadura militar 19761983" (lo anota en el pizarrón y los estudiantes toman nota en las carpetas, a modo de título); harán un repaso sobre lo último que vieron, y luego verán un video. Así, se inicia un diálogo entre profesor y estudiantes "sobre lo sucedido entre 1973 y 1976", es decir, antes del golpe de Estado. Conversan sobre la “muerte de Perón", el accionar de los "grupos revolucionarios", la violencia del grupo paraestatal "la triple A". Además, conectan con la situación argentina con la de América latina post-revolución cubana para luego volver a la escala nacional y aludir a la crítica situación económica de 1976.

Pasado ese primer momento de charla, donde se retoman contenidos trabajados en clases anteriores, el profesor anuncia que van a ver una parte del video e indica:

Bien, entonces, no vamos a escribir nada ¿sí? sino que simplemente lo vamos a ver. Yo les puse unas preguntas guía porque es con diez minutos pero como que hay mucha información en ese video... Por eso lo traje porque me parece interesante en principio para verlo. Ahora vemos cuáles son las preguntas. Lo único que tienen que hacer es tenerlas en la cabeza ¿sí? ahora las leemos entre todos, las tienen en la cabeza y van mirando el video con estas preguntas pero no anoten nada porque cuando anoten una cosa se pierden la que sigue. Si llegáramos a tener problema y lo tenemos que ver por segunda vez, lo vemos por segunda vez, no hay problema porque dura nueve_diez minutitos ¿sí?

Luego de señalar cómo van a ver el video, comenta qué van a ver (se trata del film "La república perdida 2"), ${ }^{14}$ presentando el documental, el contexto de producción y los directores:

$\mathrm{P}$ - Ahora ¿qué es lo que vamos a ver concretamente? Vamos a ver un fragmento de una película muy famosa en su momento ¿sí?, que es un documental que se llama "La República perdida 2", que es del año 1986. La fecha es MUY importante, ahora yo les voy a decir por qué. Existe una República perdida 1. Esa República perdida 1 se filmó en los últimos 
momentos de la dictadura. ¿Sí? Fueron los mismos directores que en este momento, yo les puse Miguel Pérez y Enrique Vanoli.

$\mathrm{E}-{ }_{¿}$ En los últimos momentos de esta dictadura?

P - En el 83, en los últimos momentos cuando la dictadura estaba ya en retroceso, ya iba a haber elecciones, ya se sabía la fecha de elecciones y los políticos estaban en campaña. La República perdida 1 - que no vamos a ver - habla de la historia argentina entre 1930 y el 76, ¿está?, ¿sí? De los golpes de estado, de la política, del peronismo, más o menos sería una recorrida por la historia... La república perdida 2 habla específicamente de la ÚLTIMA dictadura militar ¿sí?, de la última dictadura militar, es decir ésta que estamos viendo. Y Enrique Vanoli, de esos dos nombres que yo puse ahí, es un dirigente radical muy importante que hizo La República perdida 1 y 2, con lo cual ya esto nos da una idea de qué es lo que vamos a ver. Guarden esto como telón de fondo ahí como que el hombre es un militante y político del radicalismo, digamos que no es que es cualquier persona. Y otra cosa que quiero que observen bien es la fecha que es 1986 ¿sí? ¿Por qué es importante la fecha 1986?

$\mathrm{E}-$ ¿Después que se fueron los militares?

$\mathrm{P}$ - Después que se fueron los militares, por supuesto. Posiblemente una cosa así durante la época de los militares, ya vamos a ver, no se hubiese podido hacer ¿sí? Pero ... más que por eso es porque en diciembre del 85 ¿sí?, que esto lo vamos a ver más adelante, se termina de JUZGAR a las Juntas militares e inmediatamente sale esta película, después de que se juzga a los militares. Recuerden esto ¿sí? Surge esta película. Con lo cual ahora vamos a sospechar por qué razones la hicieron, qué intención tenían, por qué en ese momento. Tiene toda una explicación ...

En la presentación del material y el texto, el profesor ya indica la lectura que los estudiantes van a realizar: se trata, entre otras cosas, de "sospechar" razones e intenciones de los directores del film y por ello les lee las consignas de trabajo (de la guía que les presentó copia en papel para que los estudiantes tengan en sus carpetas)

$\mathrm{P}$ - Pero ahora, ¿qué quiero que miren del fragmento? Dice (lee la guía de preguntas que le entrega a los estudiantes) “ ¿Cuáles son las dificultades y 
los desafíos que tenía Perón al asumir la tercera presidencia?” Hay cosas que ya sabemos, que dijimos por acá, pero quiero que vean QUÉ dice el video, no lo que saben ustedes. Vamos a comparar con lo que nosotros sabemos, cuánto hay ahí de lo que nosotros pusimos y cuánto no. Segundo “¿Cómo la muestra a Isabel Perón?” digamos ¿sí? Van a hablar de Isabel Perón en algún momento, fíjense cómo la muestran. “QQué plantea sobre las organizaciones armadas y sobre el ejército?” ¿Cómo los muestran o cómo los presentan a las organizaciones armadas y cómo presenta el video al Ejército? “¿Qué sector es mostrado como el permanente desestabilizador y generador de los golpes de Estado?”, ¿sí?, hay un grupo que va a aparecer ahí, que para esta película siempre va a ser el enemigo constante a lo largo de la historia argentina ... Y “¿A qué políticos rescata?", vamos a ver, de repente ahí dice este es buen político, este, este ... se van a sorprender. “¿Cuál es la situación del país en cuanto a la violencia?”, ¿sí?, ¿qué valor le dan en el video, ya van a ver, a la violencia política, esta idea de la violencia armada y "qué relación tiene esa violencia con el golpe de Estado" ¿ok? Son varias cosas. Bueno, vayan leyendo mientras yo pongo la computadora y el video. Fíjense, pero no escriban nada, si no, lo vemos de vuelta, igual después lo charlamos entre todos ...

Así, el docente presenta la guía de preguntas (que luego contestarán por escrito) para que los estudiantes sepan qué van a ver y para qué lo van a ver. Lo interesante de la observación (y la transcripción aquí) es que permite acceder no solo a las consignas (que los estudiantes tienen en papel y se integrarán a las carpetas) sino a las aclaraciones, los énfasis y las explicaciones que suma el profesor en la presentación. En tal sentido, es notorio (y está resaltado ex professo) que el docente está interesado en que los alumnos adviertan no sólo lo qué dice el video sino también cómo lo dice, no separando forma de contenido.

Luego de la visualización de los diez primeros minutos del film (que dura en total 120 minutos), el profesor inicia un intercambio oral con los estudiantes retomando las preguntas de la guía. De todas las preguntas, me interesa destacar el intercambio en torno a la pregunta referida a la violencia política que vale la pena reproducir en su extensión 
$\mathrm{P}$ - ... Bien. Esto es importantísimo ¿sí? y nos va a servir para futuro y yo les dije: Acuérdense que este video se hace después del juicio a las Juntas porque acá lo que está deslizando ¿sí? sutilmente en esos primeros diez minutos el videíto, ¿sí? es que existen dos fuerzas violentas peleándose entre sí que ¿cuáles serían?

E - La de los Montoneros y...

$\mathrm{P}$ - Las Fuerzas revolucionarias armadas en general ¿y?

E - Y los militares.

P - Y los militares, obviamente. Y que el resto de esa sociedad ¿cómo está? Metida ahí adentro de esa violencia ¿y qué le pasa?

E - Que está mal económicamente y que tienen que seguir adelante sí o sí.

E - Eso. Dicen que son los que mantienen el país.

P - Bien. ¿Saben qué hacer? ¿No? están ahí como espectadores, parecía como que están por fuera ... Bueno. Quedémonos con esta idea de la violencia de las dos partes porque esto va a ser el origen, no es el origen - ya está originada desde fines de los 80 , desde finales de la dictadura -, la idea de la teoría de los dos demonios, después nosotros vamos a trabajar un texto específicamente sobre eso pero algo hablamos el 24 de marzo ¿no?

E - En ningún momento rescata la violencia o sea, no hace distinción entre la violencia sistemática del Ejército con la violencia que era simbólica

P - Bueno, no, también no era solo simbólica sino que había atentados, habíamos visto que había asesinatos y demás... Pero nosotros leímos un texto de Federico Lorenz ¿se acuerdan? que se llamaba “¿Por qué vuelven los 70"15?, allá el 24 de marzo. Y ahí él planteaba algo que discutimos ese 24 de marzo que era fundamental ¿sí? ¿Se podía equiparar ambas partes?, dice Federico Lorenz

E - No.

$\mathrm{P}$ - No. ¿Por qué no se podía equiparar ambas partes?

E - Porque una estaba avalada por el sistema y la otra no. 
P - AHÍ está. Una es el Estado ¿quién es el Estado?

E - El Ejército.

$\mathrm{P}$ - El Ejército, ojo al piojo. Por lo tanto no son equiparables, dice Federico Lorenz ... Y ahí decía: no pueden ser equiparables ni iguales justamente porque... porque uno representa al Estado ¿Puede el Estado secuestrar, matar, torturar?

$\mathrm{E}=n o=$

$\mathrm{E}=$ Se supone que no=

P - No, obviamente, NO. Es decir, la respuesta nuestra es no. Entonces, ahí está la cuestión, la cuestión digamos, la discusión. Acá (se refiere al film "La República perdida 2") parecería que se equipara. Esto le va a servir al radicalismo ¿sí? para meterse por fuera de este conflicto y decir que era un problema entre militares y las fuerzas revolucionarias armadas ¿Está? Esto va a ser desarrollado como "la teoría de los dos demonios"... Y después vamos a ver si es así, si no, pero es para más adelante ese debate, pero fíjense cómo aparece ahí en el video.

En este pasaje de la clase, se introduce una interesante discusión política, conceptual y ética. Es notorio (y lo confirma en la entrevista) que al profesor le interesa discutir la cuestión de la violencia política (que aclara que no solo es simbólica) y debatir la "teoría de los dos demonios". Para eso, retoma un texto leído a principio de año - en ocasión de la efeméride del 24 de marzo, fecha del golpe en que se conmemora el día de "la memoria, la verdad y la justicia”. Se trata de un texto periodístico, escrito por un historiador - Federico Lorenz - en el diario "Le Monde Diplomatique” titulado “¿Por qué vuelven los '70?'. En ese texto, escrito en marzo de 2017, Lorenz señalaba que en el nuevo escenario político (inaugurado a fines de 2015), sectores antes relegados, cuestionan la idea de un plan sistemático por parte de la dictadura "cívico-militar", equiparan la violencia estatal con la de las organizaciones armadas, y niegan las verdades probadas por la Justicia que fueron fundantes de la democracia argentina.

Así, entonces, ese texto le sirve al docente para discutir la "teoría de los dos demonios" que presenta la película vista. Tal narrativa habló de dos facciones armadas en los años '70 en las que existían cúpulas con autoridad (y, 
por tanto, con culpa) y señaló que hubo víctimas tanto del sector militar (impelidos a ejecutar las órdenes por el mandato de la "obediencia debida") como del lado de las organizaciones político-militares (donde los militantes de menor grado actuaron engañados). Además de esas víctimas de ambos bandos, toda la sociedad fue la víctima más inocente: primero, del fuego cruzado de los "dos demonios" de derecha e izquierda y, después, del engaño de las Fuerzas Armadas de las que sólo esperaban la pacificación del país y cometieron en cambio una represión feroz y clandestina. ${ }^{16}$ En síntesis, ese relato clausuró un debate necesario acerca de los consensos, conformidades y complicidades en torno a la dictadura; inhibió la reflexión sobre la responsabilidad de las organizaciones armadas; obliteró la revisión de las actitudes de los partidos políticos, la connivencia de los grupos empresarios, la colaboración o el silencio de los medios de comunicación, la condescendencia de la cúpula eclesiástica; en síntesis, la responsabilidad de la sociedad civil frente a la dictadura (lo que, por supuesto, no significa hablar de una sociedad como toda culpable).

Además de la discusión de representaciones y memorias, ese pasaje de la clase se cierra con una contundente manifestación de la posición ética y política sobre el tema por parte del docente: no se puede equipar la violencia de las organizaciones armadas y la violencia desde el Estado. No se puede hablar de "dos demonios" homologables. Lo plantea primero a modo de pregunta “PPuede el Estado secuestrar, matar, torturar?”. Los estudiantes contestan que no, y el docente ratifica esa respuesta: "No, obviamente, NO. Es decir, la respuesta nuestra es no". No resulta fortuito que el docente aclare "la respuesta nuestra es no" ya que está aludiendo a otras posiciones públicas que sí comparan y homologan la violencia de "izquierda y derecha" y reclaman una "memoria completa". ${ }^{17}$

Y esta lectura y discusión se entrelaza con un nuevo material, otro texto y otra lectura. Más adelante en la clase, finalizado el comentario sobre los diez minutos del video, el profesor propone trabajar un texto académico con afán divulgativo: el capítulo "El tiempo del Proceso" de Hugo Quiroga, publicado en 2005 en el libro Dictadura y democracia (1976-2001) de la colección "Nueva Historia Argentina" de editorial Sudamericana. ${ }^{18}$ Indica que lo tienen en "nuestro manual", esto es, un dossier de fotocopias con diversos materiales seleccionados por el profesor para todo el año que cada estudiante tiene para trabajar en clase. 
¿Se entendió el video más o menos? Ahora, ésta es la visión de los 80 , de mediados de los 80 . Ahora nosotros vamos a trabajar con un libro, con un texto que tenemos en nuestro manual. y que es algo más nuevo, es algo del 2005 ¿sí? Entonces lo que yo quiero que veamos es ver ¿sí?, analizar, a ver si las causas del golpe que nos dice y que vamos a trabajar en ese texto son iguales a las que están en el video o algo ha cambiado desde el 86 hasta el 2005 ¿Está? Y también tenemos la versión del 2017 porque el texto de Federico Lorenz ¿sí? era nuevo, era de este año, era de marzo de este año. ¿Está? Entonces, paren un poquito porque yo les traje el libro para mostrarles. En el capítulo que ustedes tienen, ahí yo les puse el nombre, es el tiempo del Proceso, es de este libro que se llama Nueva historia argentina, que está en el manual de ustedes ... ¿Lo tienen todos? Bien ¿Cuál es la idea? ... la idea es contestar “¿cuál es la situación del país, según Quiroga, antes del golpe de Estado?” Es decir, a ver qué pasa en comparación con el video. El segundo "¿Qué actores aparecen en el texto y que no son nombrados por el video? ¿Cuál es su rol?” A ver si aparecen actores nuevos ¿sí? vinculados al golpe de Estado que no están en el video, que nunca los nombraron, bueno, vean a ver si aparece algo nuevo ahí ¿sí? Y por supuesto que algo va a aparecer y cuál es el rol que le da Quiroga, cuál es su rol digamos ¿no? de estos nuevos grupos que aparecen ahí en el texto que en el video al parecer no aparecen. Bien. Tres “¿Cómo buscaban legitimar o justificar el golpe de Estado las Fuerzas Armadas?” Lo que dice acá de la sociedad inmadura que no está preparada para votar, vamos a ver cómo lo justifica. $Y$ “cuáles son las causas que generan el golpe de Estado según Quiroga? ¿Qué diferencia pueden marcar con las del video?” A ver si hubo cambios

Lo que le marca el profesor es continuar discutiendo la idea de una "sociedad víctima" de "dos demonios" y adentrarse en el espacio de las actitudes sociales frente a la dictadura. De allí la sugerencia del texto de Quiroga sobre la que propone una lectura histórica y una lectura historiográfica para comparar representaciones entre el texto y el documental, precisamente porque el texto introduce más actores sociales y la influencia de los medios de comunicación en las explicaciones de las causas del golpe, entre otras cuestiones.

Finalmente, y como tarea para la clase siguiente, el profesor entrega una copia de tres comunicados de la Junta Militar (selección extraída de un libro de texto escolar) que propone leer a los estudiantes fuera de clase. 
En suma, lo que queda en evidencia - con apenas una parte de una clase - es la potencia de los "textos" en distintos soportes, lenguajes y discursos y, sobre todo, la apropiación que de ellos hace el docente. Tal centralidad se repite, como se mostró en el cuadro, a lo largo de toda la secuencia que precisamente abre como cierra: con un material audiovisual. Así entonces, distintos soportes: pantalla y papel. Distintos lenguajes: el cinematográfico, el periodístico y el académico. Las diversas lecturas: históricas, historiográficas, de síntesis. Y la relevancia de las discusiones que propone el profesor sobre narrativas realizadas en tres contextos y luchas por la memoria diferentes: 1986, 2005 y 2017 que permiten ser trabajadas a partir de los materiales, textos y lecturas desplegados por ese docente.

\section{A MODO DE CIERRE}

A través de este estudio de caso, he intentado poner de manifiesto la centralidad de la materialidad en las prácticas docente para la enseñanza de la última dictadura. Materiales, textos y lecturas diversos desplegados por el profesor en el aula con discusiones históricas e historiográficas. Un docente que con distintos materiales abre debates conceptuales, políticos y éticos. Que posibilita lecturas históricas del cine y cinematográficas de la historia. Que presenta diversos lenguajes entrelazados para un debate tan relevante como pertinente: las causas del golpe y la discusión de la teoría de los dos demonios. Y todo ello potencia el trabajo de los estudiantes, los forma como lectores y espectadores, les da herramientas para ver, mirar, analizar, sospechar, deducir, comparar, interpretar etc.

Como dije al principio, la mirada sobre la escuela (y los docentes) siempre suele ser una: lo que no puede, lo que no alcanza, a lo que no se anima. Como mínimo, parece poco productivo avanzar desde allí. Poco prometedor. Poco alentador para construir saberes y prácticas.

Partir de lo que sí han podido hacer - y hacen cotidianamente - algunos profesores aparece como un camino más promisorio. E incluso puede resultar una vía más potente para la formación docente: pensar, imaginar y planear la enseñanza desde casos concretos, desde experiencias significativas y relevantes de los profesores en las aulas. Esa ha sido la apuesta de este escrito. 


\section{REFERENCIAS}

ADAMOLI, María Celeste; FARIAS, Matías; FLACHSLAND Cecilia. Educación y memoria. La historia de una política pública. Historia de la Educación, Ciudad Autónoma de Buenos Aires: SAHE, v.16, n.2, 2015. Disponible en: http://www. scielo.org.ar/scielo.php?script=sci_arttext\&pid=\$2313-92772015000200015\&lng= es\&nrm=iso; acceso: 27 dic. 2017.

ARGENTINA. Ministerio de Educación (ME). Ley de Educación Nacional. Buenos Aires: Publicaciones del Ministerio, 2006a.

ARGENTINA. Ministerio de Educación (ME). Núcleos de Aprendizajes Prioritarios Ciclo Básico de Educación Secundaria, Ciencias Sociales. Buenos Aires: Publicaciones del Ministerio, 2006b.

ARGENTINA. Ministerio de Educación (ME). Núcleos de Aprendizajes Prioritarios, Ciclo Orientado de Educación Secundaria, Ciencias Sociales. Buenos Aires: Publicaciones del Ministerio, 2012.

ARGENTINA. Provincia de Buenos Aires (PBA), Dirección General de Cultura y Educación. Diseño Curricular para la Educación Secundaria $5^{\circ}$ año: Historia. La Plata: Publicaciones de la DGCE, 2011.

ARGENTINA. Provincia de Buenos Aires (PBA), Dirección General de Cultura y Educación. Historia, 6to. Año. Escuela Secundaria Orientada. La Plata: Publicaciones de la DGCE, 2012.

BILLÁN, Yésica. El contexto como punto de partida y de llegada. Miradas en torno a la historia reciente en una institución educativa del municipio de san Miguel. Clío \& Asociados - La historia enseñada, La Plata: UNLP, v.20/21, p.237-257, 2015.

CERRUTI, Gabriela. La historia de la memoria. Entre la fetichización y el duelo. Revista Puentes, La Plata: Comisión Provincial por la Memoria, v.1, n.3, p.14-25, 2001.

DE AMÉZOLA, Gonzalo. Cambiar la historia. Manuales escolares, curriculum y enseñanza de la historia desde la transformación educativa. In: KAUFMANN, Carolina (Dir.) Dictadura y educación: los textos escolares en la historia argentina reciente. Buenos Aires: Miño y Dávila, 2006. p.227-271.

DE AMÉZOLA, Gonzalo; CARLOS, Matilde; GEOGHEGAN, Emilce. La dictadura en la escuela: la enseñanza de la historia reciente en las escuelas de la Provincia de Buenos Aires, 2006. Disponible en: http://www.riehr.com.ar/investigacion.php; acceso: 20 dic. 2017.

DE CERTEAU, Michel. La invención de lo cotidiano. Artes de hacer. Tomo I. México: Ed. Universidad Iberoamericana, 2006.

FINOCCHIO, Silvia. Clío \& Asociados. La investigación sobre enseñanza de la historia en revista. Clio \& asociados, la historia enseñada, La Plata, n.23, p.8-14, nov. 
2016b. Disponible en: http://www.clio.fahce.unlp.edu.ar/article/view/ CLIOn23a02; acceso: 20 dec. 2017.

FINOCCHIO, Silvia. Entender y vivir la educación en América Latina. In: FINOCCHIO, Silvia; NAJMANOVICH, Denise; WARSCHAUER, Mark. Diversos mundos en el mundo de la escuela. Buenos Aires: Gedisa, 2016a. p.15-76.

FINOCCHIO, Silvia; LANZA, Hilda. ¿Cómo se conforma la práctica docente? Una aproximación a los ámbitos que constituyen el discurso de los profesores de historia del nivel medio. In: LANZA, Hilda; FINOCCHIO, Silvia. Curriculum presente, ciencia ausente. Tomo III. Buenos Aires: Flacso/CIID; Miño y Dávila, 1993. p.101-181.

FRANCO, Marina. La teoría de los dos demonios en la primera etapa de la posdictadura. In: FELD, Claudia; FRANCO, Marina (Comps.) Democracia hora cero: actores políticas y debates en los inicios de la posdictadura. Buenos Aires: Siglo XXI, 2015. p.23-80.

GONZÁLEZ, María Paula. Investigaciones sobre la enseñanza de la historia en Argentina (1991-2016): un campo en expansión. Clio \& asociados, la historia enseñada, n.24, p.8-25, jun. 2017. Disponible en: http://www.clio.fahce.unlp.edu.ar/ article/view/CLIOn24a01; acceso: 15 jun. 2017.

GOSPARINI, Juan Ignacio. Entre fuentes, voces y saberes: una mirada a la conformación del saber escolar desde la materialidad de la enseñanza de la Historia argentina reciente. Clio \& asociados, la historia enseñada, La Plata: UNLP; UNL, n.23, p.51-61, 2016. Disponible en: http://www.clio.fahce.unlp.edu.ar/article/view/ CLIOn23a06; acceso: 26 dic. 2017.

HIGUERA RUBIO, Diego. La escuela ante la transmisión del pasado reciente argentino: sentidos comunes, dilemas de la representación y los desafíos del presente. Buenos Aires: Libros libres; Flacso, 2010.

LVOVICH, Daniel; BISQUERT, Jaquelina. La cambiante memoria de la dictadura: discursos públicos, movimientos sociales y legitimidad democrática. Los Polvorines: UNGS/Biblioteca Nacional, 2008.

MCEWAN, Hunter; EGAN, Kieran. La narrativa en la enseñanza, el aprendizaje y la investigación. Buenos Aires: Amorrortu, 2005.

PAPPIER, Viviana. La historia reciente en las aulas de nivel secundario: prácticas escolares en torno a la última dictadura argentina. Tesis (Maestría en Historia y Memoria) - FAHCE, Universidad Nacional de La Plata (UNLP). La Plata, 2017. Disponible en: http://sedici.unlp.edu.ar/handle/10915/61051; acceso: 3 jun. 2017.

ROMERO, Nancy. Nuevos usos del texto escolar en la escuela primaria. In: FINOCCHIO, Silvia; ROMERO, Nancy (Comps.) Saberes y prácticas escolares. Rosario: HomoSapiens, 2011. p.117-151.

STAKE, Robert. Investigación con estudios de casos. Madrid: Morata, 1998. 
VEZZETTI, Hugo. Pasado y presente: guerra, dictadura y sociedad en la Argentina. Buenos Aires: Siglo XXI, 2002.

\section{NOTAS}

${ }^{1}$ Para un panorama de las investigaciones sobre la enseñanza de la historia en general y sobre la enseñanza de la historia reciente en particular en Argentina, puede verse FINOCCHIO (2016b) y GONZÁLEZ (2017).

${ }^{2} \mathrm{El}$ análisis del tratamiento de la última dictadura en los libros de textos escolares excede el espacio de este artículo. Sobre esta cuestión, pueden verse los trabajos citados en la introducción.

${ }_{3}$ Disponible en: http://educacionymemoria.educ.ar/secundaria/wpcontent/uploads/2011/01/pensar_la_dictadura.pdf.

${ }^{4}$ Sobre el discurso y las decisiones del actual gobierno en torno a la política de memoria, verdad y justicia, pueden verse dos manifiestos de historiadores y académicos. "La democracia se construye con verdad y justicia", Diario Página/12, 22 set. 2015; "Frente a la banalización del terrorismo de Estado y los derechos humanos", Diario Perfil, 4 abr. 2017.

${ }^{5}$ Remito nuevamente a las investigaciones sobre esta cuestión reseñadas en GONZÁLEZ (2017).

${ }^{6}$ Retomo en esto último, el planteo de DE CERTEAU (2006).

${ }^{7}$ Sobre investigación con estudio de caso, puede verse STAKE (1998). Sobre la narrativa en la investigación sobre la enseñanza, MCEWAN \& EGAN (2005).

${ }^{8}$ Las investigaciones sobre materiales en la enseñanza de la historia en Argentina se han concentrado sobre todo en sus contenidos (especialmente de los libros de textos escolares) aunque trabajos más recientes han optado por indagar los usos y apropiaciones docentes por ejemplo ROMERO, 2011; GOSPARINI, 2016.

${ }^{9}$ Disponible en: https://www.youtube.com/watch?v=ymUFl-tA2WQ.

${ }^{10}$ Algunas tapas de prensa del 24 de marzo de 1976 pueden verse en: https://www.educ.ar/ recursos/129452/clarin-26-de-marzo-de-1976 https://www.educ.ar/recursos/129451/ la-nacion-25-de-marzo-de-1976.

${ }^{11}$ Disponible en: http://educacionymemoria.educ.ar/secundaria/fotos/dictadura-y-sociedad-2/attachment/2-3-viva-la-marina-la-plaza-de-galtieri/index.html.

${ }^{12} \mathrm{http}: / /$ www.telam.com.ar/notas/201504/100146-historia-mujeres-guerra-malvinas-aniversario-libro.html.

${ }^{13}$ Disponible en: https://www.youtube.com/watch?v=Q-M88abLIiU\&t=1100s.

${ }^{14}$ Disponible en: https://www.youtube.com/watch?v=XILQViWtgwM\&t=1075s. 
${ }^{15}$ Disponible en: https://www.academia.edu/32056956/_Por_qu\%C3\%A9_vuelven_los -70.

${ }^{16}$ Sobre la teoría de los dos demonios, véase CERRUTI (2001); VEZZETTI (2002); FRANCO (2015).

${ }^{17}$ Remito nuevamente al contexto político señalado en la nota 4 .

${ }^{18}$ Dicha colección es una obra colectiva de trece tomos que va desde los pueblos originarios y la conquista hasta 2001que tuvo por objetivo combinar un lenguaje divulgativo con la rigurosidad y los aportes de la historiografía de los últimos años.

Artículo recibido el 30 de diciembre de 2017. Aprobado el 27 de agosto de 2018. 